\title{
sciendo
}

\section{Focused Review on Neural Correlates of Different Types of Motor Errors and Related Terminological Issues}

\author{
by \\ Lisa Katharina Maurer ${ }^{1,2}$, Michael Joch ${ }^{1,2}$, Mathias Hegele ${ }^{1,2}$, \\ Hermann Müller ${ }^{1,2}$
}

\begin{abstract}
The Error-related negativity (Ne/ERN) and the feedback-related negativity (FRN), two event-related potentials in electroencephalogram tracings, have been used to examine error processing in conscious actions. In the classical terminology the Ne/ERN and the FRN are differentiated with respect to whether internal (Ne/ERN) or external (FRN) error information is processed. In motor tasks, however, errors of different types can be made: A wrong action can be selected that is not adequate to achieve the task goal (or action effect), or the correctly selected action can be mis-performed such that the task goal might be missed (movement error). Depending on the motor task and the temporal sequences of these events, internal and external error information can coincide. Hence, a clear distinction of the information source is difficult, and the classical terminology that differentiates the Ne/ERN and the FRN with respect to internal and external error information becomes ambiguous. But, a stronger focus on the characteristics of the definition of "task" and the cause of "errors", as well as on temporal characteristics of event-related potentials with respect to the task action allows separate examination of the processing of movement errors, the processing of the prediction of action effect errors, or the processing of the detection of action effect errors. The present article gives an overview of example studies investigating the Ne/ERN and the FRN in motor tasks, classifies them with respect to action effect errors or movement errors, and proposes updated terminology.
\end{abstract}

Key words: error-related negativity, feedback-related negativity, movement error, action effect error, error prediction, error postdiction.

\section{Introduction}

Errors in motor actions are thought to be discrepancies between an intended state and an actual state, respectively an estimate of the latter. That such a discrepancy is detected and evaluated as an error is crucial for adaptive behavior and learning. In this regard, it is interesting to investigate the time scales of error processing (when does error valuation happen?). In the last three decades, considerable research has been conducted on error processing. Neurophysiological studies in particular have sought to provide evidence for mechanisms of error processing that monitor the actual state, detect deviations from the intended state, and initiate error correction or compensation. In 1991 (Falkenstein et al., 1991) and 1993 (Gehring et al., 1993), two research teams independently reported an event-related brain potential (ERP) correlating with error responses in choice reaction time experiments. This error negativity $(\mathrm{Ne})$ or errorrelated negativity (ERN) is a negatively deflecting electroencephalogram (EEG) signal with frontocentral scalp topography peaking 50-100 ms after the erroneous response (dependent on whether response onset is measured by button press or electromyogram; Krigolson, 2018). The functional significance of the Ne/ERN has been explained by different theoretical accounts, which will not be elaborated here (for an overview see Hoffmann

\footnotetext{
1 - Neuromotor Behavior Laboratory, Department of Psychology and Sport Science, Justus Liebig University Giessen, Germany.

2 - Center for Mind, Brain and Behavior, Universities of Marburg and Giessen, Germany.
} 
and Beste, 2015), but, there is increasing evidence for the reinforcement learning hypothesis (Holroyd and Coles, 2002) that interprets the $\mathrm{Ne} / \mathrm{ERN}$ as an indicator that an action outcome is worse than expected. It is postulated that the medial frontal cortex (MFC), specifically the anterior cingulate cortex (ACC), receives an error signal from the mesencephalic dopamine system, which is then used as a training signal to adjust subsequent behavior. In addition to the Ne/ERN, a similar ERP component has been found that correlates with external error feedback. This feedback-ERN or FRN peaks about $230-350 \mathrm{~ms}$ after the presentation of a negative action outcome (Miltner et al., 1997). There is agreement that the $\mathrm{Ne} / \mathrm{ERN}$ and the FRN share the same neural source (Miltner et al., 1997; Holroyd and Coles, 2002; Holroyd et al., 2004; Gentsch et al., 2009; Walsh and Anderson, 2012), but show a clear difference in temporal location. The Ne/ERN is time-locked to the action (or response), and emerges shortly after movement onset and prior to any external feedback about the action outcome (see Fig. 1). The FRN, in contrast, is time-locked to the external outcome feedback, and is elicited after its presentation (see Fig. 1). Consequently, the reinforcement learning account posits that the $\mathrm{Ne} / \mathrm{ERN}$ reflects processes of error valuation based on internal predictions (using a copy of the efferent signals sent to the muscles). While the FRN presumably represents a postdictive error signal based on the integration of external sensory error information (Holroyd and Coles, 2002; Walsh and Anderson, 2012; Krigolson, 2018).

The Ne/ERN and the FRN have increasingly been investigated in more complex motor tasks (e.g., Krigolson and Holroyd, 2006, 2007a, 2007b; Krigolson et al., 2008; Anguera et al., 2009; Vocat et al., 2011; Torrecillos et al., 2014) as opposed to the hitherto used stimulus response tasks. However, in complex motor tasks, an error is not limited to be made on a higher cognitive level by a wrong action selection (e.g., pressing the correct or the wrong key). Errors can occur as well in the way the action is executed (even though an appropriate action might have been selected). Putting it differently, error information could either relate to the movement itself or the action effect produced by that movement. This has consequences for the valuation of an error. A mismatch can be detected between intended and actual movement parameters (such as movement kinematics or dynamics), or between intended and actual movement outcomes. The former might be correctable closed-loop (depending on the velocity of movement execution), while error valuation in the latter is the basis for a correction in subsequent trials. Hence, it becomes necessary to distinctively define the term error or to determine what part of the action is used as a source for error valuation, and to distinguish the underlying neural correlates with respect to their functions. Only with an unambiguous assignment of neural correlate and function, can the correlate be used to investigate processes of error valuation and learning. For instance, action outcome predictions are postulated to positively affect learning (Jordan and Rumelhart, 1992): The better the prediction, the better the error attribution and valuation and the better the learning. These interrelations could be examined by the neural correlate of error prediction (i.e., the Ne/ERN; Maurer et al., 2015), but only if there is certainty about the observed neural processes to clearly indicate error prediction processes.

The present article has the rationale to give an overview of example studies investigating ERPs of error valuation in motor tasks, and to classify them with respect to movement errors or action effect errors. Further, we argue that, depending on the motor task, movement and action effect, errors can coincide or can be distinct, which affects the terminology used for and the interpretation of neural effects, as we will elaborate in the following. We want to draw attention to these differences and sensitize scientists to the use of precise definitions and accurate terminology when referring to neural correlates.

Empirical findings presented to date indicate that error information is processed throughout a complete movement, starting in the planning phase, continuing during monitoring of the execution, and finally being included in the result evaluation (Desmurget and Grafton, 2000; Ridderinkhof et al., 2004). Different types of information are used for this purpose. They differ with respect to the sensory modality (e.g., visual, auditory, kinesthetic), the source of the phenomena/events (e.g., internal [to the body] vs. external events), and the parameters being described (e.g., kinematics, forces, torques etc.). For a button press movement or a reaching 
movement, movement execution (e.g., position of end effector) and action effect (position of end effector relative to a target position) can be described in an almost identical way. However, in more complex motor tasks, like targeted throwing, the movement (e.g., described by release angle and release velocity) is linked to the outcome (e.g., distance to the target) by a redundant multi-variate non-linear function imposed by the physics of the natural environment. Since error sizes in movement parameters do not necessarily map to equivalent error sizes in the outcome, these conceptual differences add to the differences observed empirically in the dissociation of movement related "low-level" errors, and actioneffect related "high-level" errors (Krigolson and Holroyd, 2006, 2007a, 2007b). High-level errors indicate that an action goal (e.g., reaching a target) has been missed or will be missed. These errors correlate with fronto-central potentials with negative polarity (de Bruijn et al., 2003; Krigolson and Holroyd, 2006, 2007a, 2007b; Krigolson et al., 2008). In contrast, low-level errors in movement execution (e.g., a deviation from a designated movement trajectory) are mostly connected to activity in the posterior parietal cortex (Desmurget et al., 1999; Desmurget and Grafton, 2000; Krigolson and Holroyd, 2006, 2007b; Krigolson et al., 2008). Importantly, these trajectory discrepancies can be corrected in principal, such that the action outcome is still achieved (Krigolson and Holroyd, 2007b). However, in cases where a correction fails, the action goal will be missed and, thus, the low-level movement error leads to a highlevel error. Since the valuation of low-level and high-level errors is based on different information, it is necessary to differentiate two types of feedback. On the one hand, there is feedback about a specific sensory pattern that signals the success or failure of a movement after termination of that movement. For instance, the distance between the end position of a cursor and a target is visually obtained in a manual aiming task. On the other hand, incoming feedback during the movement can include information about movement execution without revealing clear information about terminal movement success. This information, however, can be used to estimate the terminal movement outcome. Thus, high-level errors in motor tasks can either be evaluated by prediction on the basis of a preceding low-level error transmitted by movement feedback or evaluated by postdiction (detected) after the presentation of feedback about the terminal action effect (success or failure).

To date, and as stated above, ERP components correlating with error processing have been defined and distinguished based on whether internal (movement related) or external (outcomefeedback related) error information is processed. External information has been equated with feedback in general, without differentiating between the content of feedback information. We believe that this distinction is inadequate for research on error processing in motor learning, since the essential drive for learning is information about the success of a movement (with less significance on the locus of information). Hence, we suggest to structure the definition of errors with respect to their information content (high-level or action-effect error vs. low-level or movement error). In addition, ERP components representing the processing of action effect errors need to be differentiated with respect to the type of error valuation: whether the error is predicted or postdicted. The ERP representing prediction could function as a measure of learning. In this regard, we have searched through recent publications to find tasks that examined ERPs of movement error valuation and action effect error valuation in motor tasks. We will first briefly describe the empirical procedures and findings of the studies, which will be followed by our argumentation in favor of an adapted terminology regarding the Ne/ERN and the FRN, concluding with a classification of the selected studies. It is important to emphasize that this review addresses terminological issues related to the examination of the Ne/ERN and the FRN in motor tasks, and it is not its goal to summarize the theoretical and neural underpinnings of these components. Hence, the studies reviewed instead represent examples, and there is no claim made for completeness.

\section{ERP Studies on motor error processing}

\section{Studies with action effect errors}

Kieffaber (Kieffaber et al., 2016) analyzed ERPs in a cued task-set switching task where two symbols had to be rated according to shape or color congruency. Responses required continuous reaching movement with a mouse curser to two different response areas on the computer screen, and deviations could be corrected by the subjects 
online. ERPs were synchronized with respect to movement initiation and also error correction. The authors found a distinct negative signal that occurred with the initiation of erroneous movements irrespective of whether the error was corrected afterwards or not. This result indicates that the signal represents an error prediction process. Neither external information about response success nor any afferent information from movement execution could have been integrated into the prediction process. However, the rapidness of the error prediction (shortly after the movement had been initiated) indicates that the error was made on the cognitive level (wrong response decision) rather than on the motor level. Hence, the prediction might be confined to the action effect.

Krigolson and Holroyd conducted a series of cleverly designed experiments to investigate the function of the Ne/ERN and the FRN (Krigolson and Holroyd, 2006, 2007a, 2007b). In 2007 (a), participants executed a tracking task with the goal of keeping a cursor on a computer screen between two predictably moving barriers. However, in some trials the barriers moved fast and unpredictably, so that the cursor always contacted the barriers (i.e., an error occurred). Further, in half of these trials the cursor was controlled by the computer, so that an error was prevented (the cursor was kept between the barriers). Participants received predictive feedback indicating an error $500 \mathrm{~ms}$ before a barrier was contacted in the form of a visual cue (explicit feedback: blue or green square for error and correct, respectively), or tactilely via a reduction in joystick control (a comparison between an internal motor command and its behavioral/proprioceptive consequence). Since errors always occurred after the cue, participants did not make incorrect movements, and they could not correct the errors, we would classify the errors in this task as action effect errors. Both variants of predictive feedback elicited a negative error signal peaking, respectively, $66 \mathrm{~ms}$ after barrier contact (explicit visual) and $32 \mathrm{~ms}$ prior to barrier contact (comparison internalbehavior). The mapping of the visual cue-to-error and the proprioceptive cue-to-error had to be learned. Hence, the neural error signals starting off before the cursor hit the barriers predicted that cursor hit, causing the authors to interpret them as $\mathrm{Ne} / \mathrm{ERN}$ signals. However, one can argue that both mappings are relatively simple, and, once learned, the cues substitute for the former sensory error feedback pattern (the cursor hitting one of the barriers), and represent explicit error feedback about the action effect. The difference in latency between the two cues might be due to a more direct (and thereby easier to learn) relationship between the lost joystick control and the error occurrence, compared to the relationship between the visual cue and the error occurrence.

Lutz and colleagues (Lutz et al., 2013) examined error processing in an auditory-motor task. They had participants reproduce piano tones on an electronic keyboard, and found two frontocentral negative signals: The first one peaked shortly ( 100 ms) after an erroneous keystroke (and a simultaneous wrong tone); the second was observed about $230 \mathrm{~ms}$ after keystroke and tone. In addition to these internal errors, external errors (wrong tones despite correct keystrokes) were generated in $50 \%$ of the actually correct trials. These external error trials were only correlated with a later fronto-central negativity, peaking 230 ms after a keystroke. As participants had to reproduce piano tones one after the other as opposed to playing a sequence of tones, the production of wrong tones can be interpreted as decision errors with respect to the action effect. The observed ERP signals differed with respect to their predictive character. The earlier signal occurred before any information about the action effect could be processed, and can, therefore, be interpreted as representing a prediction of the action effect error, whereas the later signal indicates postdiction of the action effect error.

\section{Studies with separate movement and action effect errors}

In an interesting study, de Bruijn and colleagues (de Bruijn et al., 2003) examined different types of self-induced errors in a force production task. Participants had to react in response to four different stimuli with the production of a high force $(28-56 \%$ maximal voluntary contraction, MVC) or a low force (14-28 $\% \mathrm{MVC}$ ) with their right or left index fingers. Errors in the choice of hand (e.g., left instead of right finger) and force (e.g., high instead of low force) were followed by clear negative activity in fronto-central regions $110 \mathrm{~ms}$ and $135 \mathrm{~ms}$ after response onset and prior to visual result feedback, at least in the low force conditions. These signals 
can be interpreted as predictive signals with respect to the action effect. Inaccurately exerted forces, however, which represented errors in movement execution, did not elicit negativity in the ERP in the analyzed time window (0-200 ms after response onset). Since force production was still in progress until, on average, $139 \mathrm{~ms}$ after response onset, it is plausible that error valuation with respect to the goal force range had not yet been terminated at that point in time. As the authors themselves claim: "...it is not certain whether representations of the responses are available to the system at the moment of response onset...", which indicates that error valuation of a force production process is seemingly more complex than error valuation of a discrete response selection. Hence, predictive valuation of the correct force range might have needed more time and/or more information from afferent channels to integrate with information from the efference copy to yield a more reliable prediction. It cannot be excluded that an error-related signal could have been observed later than $200 \mathrm{~ms}$ after response onset, in particular because correct trials and trials with inaccurately exerted forces tended to differ over a larger time period beyond the determined time window, as can be observed in Fig. 3 of de Bruijn and colleagues (de Bruijn et al., 2003).

\section{Studies with related movement and action effect errors}

Vocat et al. (Vocat et al., 2011) examined ballistic pointing movements with and without prism goggles to varying targets on a touch screen. Participants did not see their hands reaching towards the target until they approached the screen (unfortunately, the authors did not indicate how long before the touching of the screen subjects could see their hands). EEG activity measurement was synchronized to the moment when the subject's finger touched the screen (response). At $76 \mathrm{~ms}$ after the response, a negative deflection was observed, that the authors interpreted as Ne/ERN. Since detection of a prism perturbation error can only be made by comparing the target position (and/or the intended response) with the actually perceived response (finger position with respect to target position), we assume that participants must have been able to observe their hands long enough before touching the screen such that afferent information could be processed, and failure to reach the target could be predicted, which manifested $76 \mathrm{~ms}$ after the response. Thus, the actually perceived movement parameters and their deviation from the intended parameters imply a prediction about the action effect (missing the target).

In a somewhat similar visuomotor adaptation task (virtual rotation on a computer screen) Anguera and colleagues (Anguera et al., 2009) observed a slow-moving negative waveform timelocked to the initiation of perturbed targeted reaching movements. Akin to the prism perturbation task of Vocat et al. (2011), the perturbation here was also externally induced. Hence, error valuation also had to be based on incoming afferent information about the movement, which is supported by the signal-onset time of about $100 \mathrm{~ms}$ after movement initiation. The signal had a predictive character as well, since the action effect (reaching a target circle on the screen) had not yet been achieved at that point in time.

Torrecillos and colleagues (Torrecillos et al., 2014) used a ballistic force field adaptation task to measure these effects. Participants were instructed to execute ballistic reaching movements with their arms resting on a robotic device and with the aim of reaching a target ring by "shooting" in a given direction. Feedback was presented dependent on the reaching duration, with negative feedback provided if the movement was more than $50 \mathrm{~ms}$ slower or faster than the "goal duration" (375 ms). At times, the reaching movement was perturbed such that movement kinematics deviated from the specified path. ERPs were synchronized with respect to movement onset and feedback time (presented when reaching the target ring). Kinematic deviations in the perturbed trials gave rise to a fronto-central negative signals $270 \mathrm{~ms}$ and $305 \mathrm{~ms}$ after movement onset (dependent on the size of the deviation), and about $310 \mathrm{~ms}$ after feedback. As in the previous studies, the external perturbations led to a mismatch between intended and actual movement parameters. Although the authors specified that kinematic errors were not directly related to the task goal (i.e., to meet the instructed movement duration), it is very likely that the kinematic low-level errors "related to a feeling of losing control" (Torrecillos et al., 2014) might have been experienced as a predictive sign with respect to missing the task goal.

In their study from 2006, Krigolson and 
Holroyd again used the tracking task with the moving barriers. Similar to the study described above, the barriers moved quickly and unpredictably in $20 \%$ of the trials. In half of these trials the cursor was controlled by the computer, so that an error was prevented (the cursor was kept between the barriers), while in the other half of the trials participants had control over the cursor, but the speed of the unpredictable barrier movement provoked a barrier contact. These externally provoked errors, as well as regular self-induced barrier contacts (from the other $80 \%$ of trials) entailed larger negative activations of frontocentral regions relative to trials where errors were prevented (i.e., trials on target). The onset of these negative signals was prior to barrier contact (and the peak shortly thereafter), indicating that they both represent a predictive valuation with respect to the barrier contact (action effect). Importantly, as errors in the fast and unpredictable condition were externally manipulated, their detection/valuation could only be based on the comparison between intended/predicted movement parameters and incoming afferent information about actual movement parameters, whereas regular selfinduced errors might have relied merely on efferent information. Both ERP signals share, however, the same topographic and temporal features, and have the same amplitude. In addition to the frontal signals, the authors also found a negative ERP in occipital-parietal areas, peaking about $155 \mathrm{~ms}$ after barrier contact. They interpreted this signal as related to adaptive modification of behavior.

In a series of studies, Maurer and colleagues $(2015 ; 2017 ; 2018)$ investigated error valuation and neural correlates in a computer-based goaloriented throwing task. Participants had to throw a ball towards a target using a lever device. Release of the ball was executed by the subjects releasing their index finger from a lever handle. The mapping of the task was not intuitive, hence it had to be learned. The authors found a negatively peaking fronto-central ERP signal about $250 \mathrm{~ms}$ after ball release in trials in which subjects missed the target in all experiments, and a second similarly distributed signal $200 \mathrm{~ms}$ after the miss was actually observable on the computer screen (Joch et al., 2017; Joch et al., 2018). Since the throwing movement was terminated with ball release, efferent information as well as incoming afferent information might have contributed to the error signal 250 ms later (Jeannerod, 1988). At that moment, however, the action effect could not be known, and, hence must have been predicted on the basis of the movement error. The detection of the action effect error by seeing the ball missing the target then correlated with the second ERP signal. Interestingly, the authors masked the ball flight towards the target in their 2017 and 2018 studies, so that participants could not make use of the trajectory information of the ball approaching the target. This manipulation did not change the ERP effects in general. Only the amplitude of the predictive signal was slightly reduced, which could also be explained by a simultaneous drop in performance.

\section{Studies with varying error types}

Bediou and colleagues presented a study in 2012 (Bediou et al., 2012) where action effect errors and movement errors could have been made. They used a Go/NoGo shooting task, and found a negative EEG signal related to predictive processes (onset simultaneously with shooting response) in commission errors (participants erroneously shot in the NoGo condition), but not in accuracy errors (participants missed the target in the Go condition). Commission errors were interpreted as decision errors on the basis of internal motor representations. Hence, the correlated ERP signals predicted the shooting outcome (action effect). In contrast, accuracy errors were followed by a negative signal at about $230 \mathrm{~ms}$ after response, and simultaneous response feedback (curser position with respect to target). These results were interpreted as shooting execution errors, which seemingly needed more processing time and/or additional external information sources (response feedback). Unfortunately, the authors did not set a delay between shooting response and response feedback. Hence, they could not differentiate between action and movement, which would have been easily possible with their virtual shooting task. This decision did not allow the examination of whether additional afferent information about shooting execution integrated with efferent information (but without external information), and would have sufficed to predict an accuracy error.

In the second study from 2007(b), Krigolson and Holroyd used a computer-based manual aiming task. In two experimental conditions, the target 
position was changed after participants started their reaching movement with a joystick. They could correct towards the new position in the first condition (correctable). In the second condition, the cursor on the monitor did not respond to the joystick movement (uncorrectable), and, hence, an error was provoked. ERPs were analyzed with respect to the movement onset (parallel to target perturbation), and with respect to the onset of the corrective movement. The authors did not find negative signals in fronto-central regions in the correctable condition, but did find these signals in the uncorrectable condition. These signals did, however, emerge about $250 \mathrm{~ms}$ after the corrective movement. The authors interpreted their results with the focus on the difference between low-level and high-level errors. The target perturbation entailed discrepancies between intended and actual motor commands (i.e., low-level movement error). As these discrepancies could, in principle, be corrected, failure to achieve the task goal (highlevel action effect error) was not predicted, and an $\mathrm{Ne} / \mathrm{ERN}$ not expected. In contrast, when the corrective movement was blocked (in the uncorrectable condition), the target could not be reached, and the negativity occurring after the attempt to correct signaled the prediction of the action effect error. Krigolson and Holroyd labeled this negativity feedback ERN, because losing control over the joystick indicated that the task goal would definitely be missed (similar to the cue in Krigolson and Holrody 2007a).

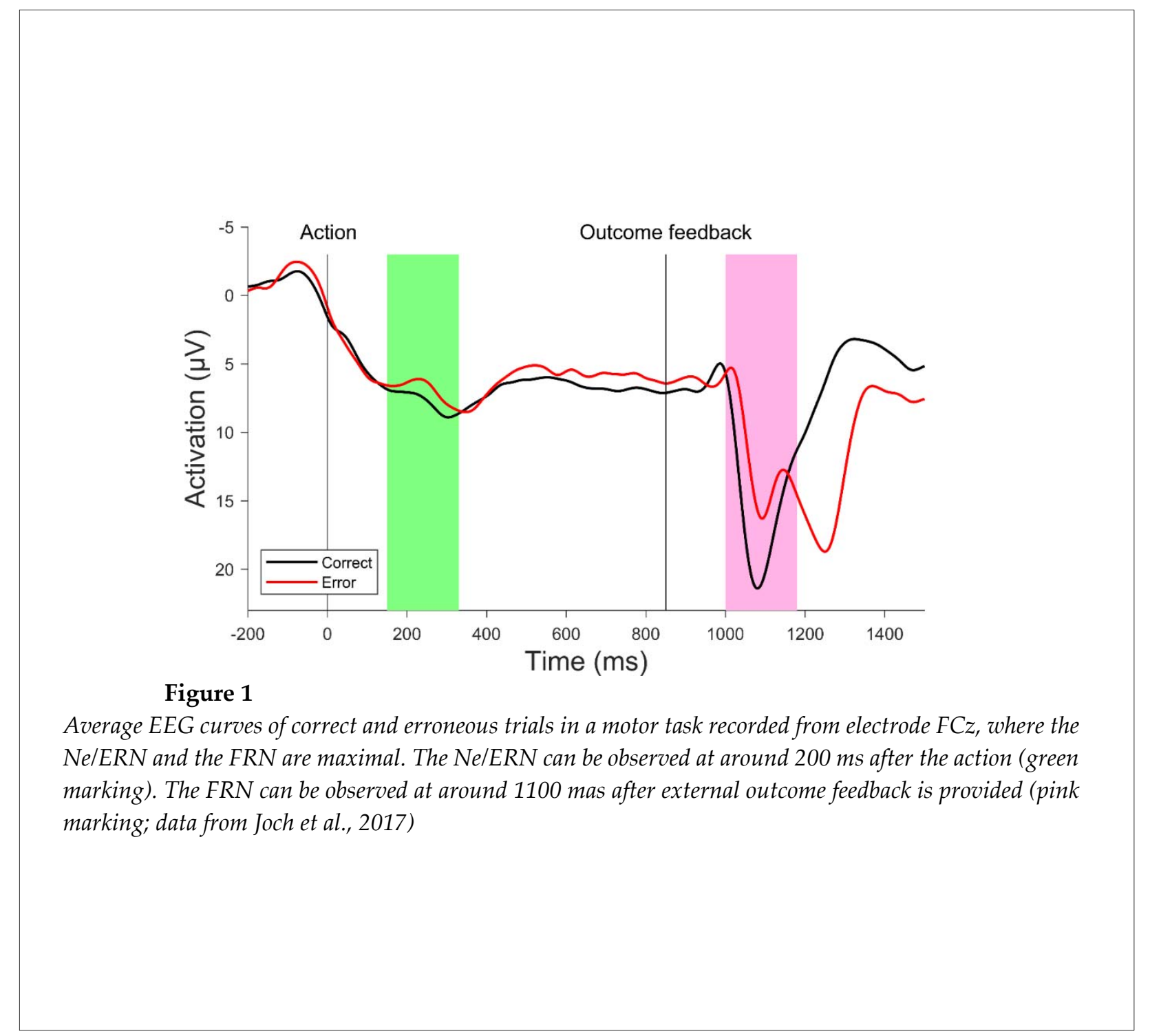




\begin{tabular}{|c|c|c|c|c|}
\hline $\begin{array}{l}\text { Error Valuation } \\
\text { Interval }\end{array}$ & \multicolumn{3}{|c|}{$\begin{array}{l}\text { Prediction } \\
\text { Error Valuation prior to TAEF }\end{array}$} & $\begin{array}{c}\text { Postdiction } \\
\text { Error Valuation after TAEF }\end{array}$ \\
\hline $\begin{array}{l}\text { Information } \\
\text { Sources }\end{array}$ & $\begin{array}{l}\text { Internal } \\
\text { Efferent } \\
\text { Information }\end{array}$ & $\begin{array}{l}\text { Sensory Information (e.g. } \\
\text { Proprioception, Vision) }\end{array}$ & External Visual Information & External Visual Information \\
\hline \multirow{2}{*}{ Action Phases } & $\begin{array}{l}\text { Movement } \\
\text { Planning }\end{array}$ & Movement Execution & Action Effect & $\begin{array}{l}\text { Terminal Action Effect } \\
\text { Feedback (TAEF) }\end{array}$ \\
\hline & & start & & \\
\hline $\begin{array}{l}\text { Comparisons for } \\
\text { Error Valuation }\end{array}$ & $\begin{array}{r}E^{\prime}(t+\Delta t) \\
\leftrightarrow \widehat{E}(t+\Delta t)\end{array}$ & $\begin{array}{l}\left(\alpha^{*}{ }_{1}(t), \alpha^{*}{ }_{2}(t), \ldots, \alpha^{*}{ }_{n}(t)\right) \\
\leftrightarrow\left(\alpha_{1}(t), \alpha_{2}(t), \ldots, \alpha_{n}(t)\right) \\
\boldsymbol{E}^{\prime}(t+\Delta t) \leftrightarrow \widehat{E}(t+\Delta t)\end{array}$ & $E^{*}(t+\Delta t) \leftrightarrow \widehat{E}(t+\Delta t)$ & $\begin{array}{l}E^{*}(t+\Delta t) \leftrightarrow E(t+\Delta t) \\
\widehat{E}(t+\Delta t) \leftrightarrow E(t+\Delta t)\end{array}$ \\
\hline
\end{tabular}

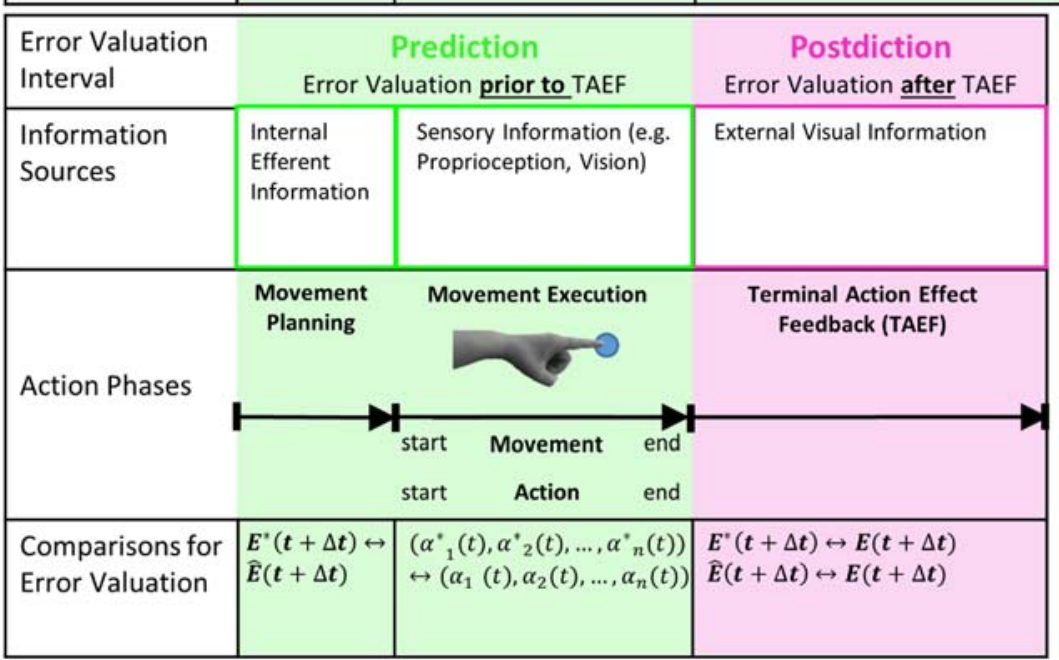

Figure 2

Different variables of the error valuation process in two different tasks, basketball shooting and button pressing: (1) error valuation interval: error valuation can take place prior to terminal action effect feedback (TAEF) or after TAEF, (2) information sources: internal or external sensory sources that provide information to evaluate the action, (3) action phases: an action can be differentiated into movement planning, movement execution, action effect, and terminal action effect (action outcome) feedback. The whole action comprises movement execution and action effect, which coincide in simple tasks like button pressing, but are separate in other tasks like shooting; (4) comparisons of error valuation: possible computations that are made in order to evaluate the action and detect an error. Detailed explanations are found in the main text. 
Table 1

Studies investigating error processing in motor tasks, sorted by type of error

\begin{tabular}{|c|c|c|c|c|c|c|c|c|}
\hline Study & Task & $\begin{array}{l}\text { Type of } \\
\text { Error }\end{array}$ & $\begin{array}{l}\text { Source of } \\
\text { Error } \\
\text { Information }\end{array}$ & \multicolumn{2}{|c|}{$\begin{array}{l}\text { ERP Signals (with respect to } \\
\text { response/feedback) }\end{array}$} & $\begin{array}{l}\text { Time Course of } \\
\text { Error Valuation } \\
\text { as represented by } \\
\text { FRP }\end{array}$ & $\begin{array}{l}\text { Authors' } \\
\text { Termino- } \\
\text { logy }\end{array}$ & $\begin{array}{l}\text { Proposed } \\
\text { Termino- } \\
\text { logy }\end{array}$ \\
\hline $\begin{array}{l}\text { Kieffaber } \\
\text { et al. } 2016\end{array}$ & $\begin{array}{l}\text { cued } \\
\text { task-set } \\
\text { switching } \\
\text { task with } \\
\text { reaching } \\
\text { move- } \\
\text { ments } \\
\end{array}$ & $\begin{array}{l}\text { action } \\
\text { effect error } \\
\text { (decision } \\
\text { error) }\end{array}$ & internal & $\begin{array}{l}\text { negative } \\
\text { fronto-central } \\
\text { ERP }\end{array}$ & $\begin{array}{l}\sim 50 \mathrm{~ms} \text { after } \\
\text { response }\end{array}$ & $\begin{array}{l}\text { prediction of } \\
\text { action effect error }\end{array}$ & ERN & $\mathrm{Ne} / \mathrm{ERN}$ \\
\hline $\begin{array}{l}\text { Krigolson } \\
\text { and } \\
\text { Holroyd } \\
2007 a\end{array}$ & $\begin{array}{l}\text { tracking } \\
\text { task }\end{array}$ & $\begin{array}{l}\text { action } \\
\text { effect error } \\
\text { (predictive } \\
\text { external } \\
\text { cue) }\end{array}$ & $\begin{array}{l}\text { external with } \\
\text { respect to } \\
\text { action effect }\end{array}$ & $\begin{array}{l}\text { negative } \\
\text { fronto-central } \\
\text { ERP }\end{array}$ & $\begin{array}{l}32 \text { ms / } 66 \\
\text { ms before } \\
\text { feedback } \\
\text { (dependent } \\
\text { on modality } \\
\text { of external } \\
\text { cue) }\end{array}$ & $\begin{array}{l}\text { postdiction of } \\
\text { action effect error }\end{array}$ & $\begin{array}{l}\text { ERN-like } \\
\text { waveform }\end{array}$ & FRN \\
\hline \multirow{3}{*}{$\begin{array}{l}\text { Lutz et al. } \\
2013\end{array}$} & \multirow{3}{*}{$\begin{array}{l}\text { piano } \\
\text { tone } \\
\text { repro- } \\
\text { duction } \\
\text { task }\end{array}$} & \multirow{2}{*}{$\begin{array}{l}\text { action } \\
\text { effect error } \\
\text { (decision } \\
\text { error) }\end{array}$} & internal & $\begin{array}{l}\text { negative } \\
\text { fronto-central } \\
\text { ERP }\end{array}$ & $\begin{array}{l}\sim 100 \mathrm{~ms} \\
\text { after } \\
\text { response/ } \\
\text { feedback }\end{array}$ & $\begin{array}{l}\text { prediction of } \\
\text { action effect error }\end{array}$ & ERN & $\mathrm{Ne} / \mathrm{ERN}$ \\
\hline & & & $\begin{array}{l}\text { external with } \\
\text { respect to } \\
\text { action effect }\end{array}$ & $\begin{array}{l}\text { negative } \\
\text { fronto-central } \\
\text { ERP }\end{array}$ & $\begin{array}{l}\sim 230 \mathrm{~ms} \\
\text { after } \\
\text { response/ } \\
\text { feedback }\end{array}$ & $\begin{array}{l}\text { postdiction of } \\
\text { action effect error }\end{array}$ & FRN & FRN \\
\hline & & $\begin{array}{l}\text { action } \\
\text { effect error } \\
\text { (externally } \\
\text { induced) }\end{array}$ & $\begin{array}{l}\text { external with } \\
\text { respect to } \\
\text { action effect }\end{array}$ & $\begin{array}{l}\text { negative } \\
\text { fronto-central } \\
\text { ERP }\end{array}$ & $\begin{array}{l}\sim 230 \mathrm{~ms} \\
\text { after } \\
\text { response/ } \\
\text { feedback }\end{array}$ & $\begin{array}{l}\text { postdiction of } \\
\text { action effect error }\end{array}$ & FRN & FRN \\
\hline \multirow[t]{2}{*}{$\begin{array}{l}\text { de Bruijn } \\
\text { et al. } 2003\end{array}$} & \multirow[t]{2}{*}{$\begin{array}{l}\text { force } \\
\text { produc- } \\
\text { tion task }\end{array}$} & $\begin{array}{l}\text { action } \\
\text { effect error } \\
\text { (decision } \\
\text { error) }\end{array}$ & internal & $\begin{array}{l}\text { negative } \\
\text { fronto-central } \\
\text { ERP }\end{array}$ & $\begin{array}{l}110 \text { ms / } 135 \\
\text { ms after } \\
\text { response } \\
\text { (dependent } \\
\text { on error in } \\
\text { choice of } \\
\text { hand or } \\
\text { force), but } \\
\text { before } \\
\text { feedback }\end{array}$ & $\begin{array}{l}\text { prediction of } \\
\text { action effect error }\end{array}$ & $\mathrm{Ne} / \mathrm{ERN}$ & $\mathrm{Ne} / \mathrm{ERN}$ \\
\hline & & $\begin{array}{l}\text { movement } \\
\text { error }\end{array}$ & internal & \multicolumn{2}{|c|}{$\begin{array}{l}\text { no significant negative fronto- } \\
\text { central ERP }\end{array}$} & - & - & - \\
\hline $\begin{array}{l}\text { Vocat et } \\
\text { al. } 2011\end{array}$ & $\begin{array}{l}\text { ballistic } \\
\text { pointing } \\
\text { task with } \\
\text { prism } \\
\text { perturba- } \\
\text { tion }\end{array}$ & $\begin{array}{l}\text { movement } \\
\text { error leads } \\
\text { to action } \\
\text { effect error }\end{array}$ & $\begin{array}{l}\text { external with } \\
\text { respect to } \\
\text { movement }\end{array}$ & $\begin{array}{l}\text { negative } \\
\text { fronto-central } \\
\text { ERP }\end{array}$ & $\begin{array}{l}76 \text { ms after } \\
\text { response/ } \\
\text { feedback }\end{array}$ & $\begin{array}{l}\text { prediction of } \\
\text { action effect error }\end{array}$ & ERN & $\mathrm{Ne} / \mathrm{ERN}$ \\
\hline $\begin{array}{l}\text { Anguera } \\
\text { et al. } 2009\end{array}$ & $\begin{array}{l}\text { visuo- } \\
\text { motor } \\
\text { adap- } \\
\text { tation } \\
\text { task }\end{array}$ & $\begin{array}{l}\text { movement } \\
\text { error leads } \\
\text { to action } \\
\text { effect error }\end{array}$ & $\begin{array}{l}\text { external with } \\
\text { respect to } \\
\text { movement }\end{array}$ & $\begin{array}{l}\text { negative } \\
\text { fronto-central } \\
\text { ERP }\end{array}$ & $\begin{array}{l}\text { onset about } \\
100 \text { ms after } \\
\text { response, } \\
\text { peak about } \\
600 \text { ms after } \\
\text { response, } \\
\text { but before } \\
\text { feedback }\end{array}$ & $\begin{array}{l}\text { prediction of } \\
\text { action effect error }\end{array}$ & $\begin{array}{l}\text { ERN- } \\
\text { related } \\
\text { activity }\end{array}$ & $\mathrm{Ne} / \mathrm{ERN}$ \\
\hline
\end{tabular}




\begin{tabular}{|c|c|c|c|c|c|c|c|c|}
\hline \multirow[t]{2}{*}{$\begin{array}{l}\text { Torrecillo } \\
\text { s et al. } \\
2014\end{array}$} & \multirow[t]{2}{*}{$\begin{array}{l}\text { ballistic } \\
\text { force } \\
\text { field } \\
\text { adap- } \\
\text { tation } \\
\text { task }\end{array}$} & \multirow[t]{2}{*}{$\begin{array}{l}\text { movement } \\
\text { error leads } \\
\text { to action } \\
\text { effect error }\end{array}$} & $\begin{array}{l}\text { external with } \\
\text { respect to } \\
\text { movement }\end{array}$ & $\begin{array}{l}\text { negative } \\
\text { fronto-central } \\
\text { ERP }\end{array}$ & $\begin{array}{l}270-305 \mathrm{~ms} \\
\text { after } \\
\text { response } \\
\text { (dependent } \\
\text { on the size } \\
\text { of } \\
\text { deviation), } \\
\text { but before } \\
\text { feedback }\end{array}$ & $\begin{array}{l}\text { prediction of } \\
\text { action effect error }\end{array}$ & $\begin{array}{l}\text { ERP-K } \\
\text { (induced } \\
\text { by } \\
\text { kinematic } \\
\text { error) }\end{array}$ & $\mathrm{Ne} / \mathrm{ERN}$ \\
\hline & & & $\begin{array}{l}\text { external with } \\
\text { respect to } \\
\text { action effect }\end{array}$ & $\begin{array}{l}\text { negative } \\
\text { fronto-central } \\
\text { ERP }\end{array}$ & $\begin{array}{l}\sim 310 \mathrm{~ms} \\
\text { after } \\
\text { feedback }\end{array}$ & $\begin{array}{l}\text { postdiction of } \\
\text { action effect error }\end{array}$ & FRN & FRN \\
\hline \multirow{3}{*}{$\begin{array}{l}\text { Krigolson } \\
\text { and } \\
\text { Holroyd } \\
2006\end{array}$} & \multirow{3}{*}{$\begin{array}{l}\text { tracking } \\
\text { task }\end{array}$} & \multirow{3}{*}{$\begin{array}{l}\text { movement } \\
\text { error leads } \\
\text { to action } \\
\text { effect error }\end{array}$} & \multirow[t]{2}{*}{$\begin{array}{l}\text { external with } \\
\text { respect to } \\
\text { movement }\end{array}$} & $\begin{array}{l}\text { negative } \\
\text { fronto-central } \\
\text { ERP }\end{array}$ & $\begin{array}{l}\text { onset } 26 \mathrm{~ms} \\
\text { before } \\
\text { feedback, } \\
\text { peak } 73 \mathrm{~ms} \\
\text { after } \\
\text { feedback }\end{array}$ & $\begin{array}{l}\text { prediction of } \\
\text { action effect error }\end{array}$ & $\begin{array}{l}\text { response } \\
\text { ERN }\end{array}$ & $\mathrm{Ne} / \mathrm{ERN}$ \\
\hline & & & & $\begin{array}{l}\text { negative occi- } \\
\text { pital-parietal } \\
\text { ERP }\end{array}$ & $\begin{array}{l}\text { peak } 155 \mathrm{~ms} \\
\text { after feed- } \\
\text { back }\end{array}$ & $\begin{array}{l}\text { detection of } \\
\text { movement error }\end{array}$ & - & - \\
\hline & & & internal & \multicolumn{2}{|c|}{$\begin{array}{l}\text { similar ERPS relative to } \\
\text { external error information }\end{array}$} & $\begin{array}{l}\text { prediction of } \\
\text { action effect error }\end{array}$ & $\begin{array}{l}\text { response } \\
\text { ERN }\end{array}$ & $\mathrm{Ne} / \mathrm{ERN}$ \\
\hline \multirow{2}{*}{$\begin{array}{l}\text { Maurer et } \\
\text { al. 2015; } \\
\text { Joch et al. } \\
2017,2018\end{array}$} & \multirow{2}{*}{$\begin{array}{l}\text { computer } \\
\text { based } \\
\text { goal- } \\
\text { oriented } \\
\text { throwing } \\
\text { task }\end{array}$} & \multirow{2}{*}{$\begin{array}{l}\text { movement } \\
\text { error leads } \\
\text { to action } \\
\text { effect error }\end{array}$} & $\begin{array}{l}\text { internal and } \\
\text { external with } \\
\text { respect to } \\
\text { movement }\end{array}$ & $\begin{array}{l}\text { negative } \\
\text { fronto-central } \\
\text { ERP }\end{array}$ & $\begin{array}{l}\text { 250 ms } \\
\text { after } \\
\text { response, } \\
\text { but before } \\
\text { feedback }\end{array}$ & $\begin{array}{l}\text { prediction of } \\
\text { action effect error }\end{array}$ & $\mathrm{Ne} / \mathrm{ERN}$ & $\mathrm{Ne} / \mathrm{ERN}$ \\
\hline & & & $\begin{array}{l}\text { external with } \\
\text { respect to } \\
\text { action effect }\end{array}$ & $\begin{array}{l}\text { negative } \\
\text { fronto-central } \\
\text { ERP }\end{array}$ & $\begin{array}{l}\sim 200 \mathrm{~ms} \\
\text { after } \\
\text { feedback }\end{array}$ & $\begin{array}{l}\text { postdiction of } \\
\text { action effect error }\end{array}$ & FRN & FRN \\
\hline \multirow{2}{*}{$\begin{array}{l}\text { Bediou et } \\
\text { al. } 2012\end{array}$} & \multirow{2}{*}{$\begin{array}{l}\text { Go/NoGo } \\
\text { shooting } \\
\text { task }\end{array}$} & $\begin{array}{l}\text { action } \\
\text { effect error } \\
\text { (decision } \\
\text { error) } \\
\end{array}$ & internal & $\begin{array}{l}\text { negative } \\
\text { fronto-central } \\
\text { ERP }\end{array}$ & $\begin{array}{l}58 \text { ms after } \\
\text { response/ } \\
\text { feedback }\end{array}$ & $\begin{array}{l}\text { prediction of } \\
\text { action effect error }\end{array}$ & ERN & $\mathrm{Ne} / \mathrm{ERN}$ \\
\hline & & $\begin{array}{l}\text { movement } \\
\text { error leads } \\
\text { to action } \\
\text { effect error }\end{array}$ & $\begin{array}{l}\text { internal and } \\
\text { external with } \\
\text { respect to } \\
\text { action effect }\end{array}$ & $\begin{array}{l}\text { negative } \\
\text { fronto-central } \\
\text { ERP }\end{array}$ & $\begin{array}{l}227 \text { ms after } \\
\text { response/ } \\
\text { feedback }\end{array}$ & $\begin{array}{l}\text { postdiction of } \\
\text { action effect error }\end{array}$ & FRN & FRN \\
\hline \multirow{2}{*}{$\begin{array}{l}\text { Krigolson } \\
\text { and } \\
\text { Holroyd } \\
2007 b\end{array}$} & \multirow{2}{*}{$\begin{array}{l}\text { computer } \\
\text { based } \\
\text { manual } \\
\text { aiming } \\
\text { task }\end{array}$} & $\begin{array}{l}\text { action } \\
\text { effect error }\end{array}$ & $\begin{array}{l}\text { external with } \\
\text { respect to } \\
\text { action effect }\end{array}$ & $\begin{array}{l}\text { negative } \\
\text { fronto-central } \\
\text { ERP }\end{array}$ & $\begin{array}{l}\sim 500 \mathrm{~ms} \\
\text { after } \\
\text { response, } \\
\text { but before } \\
\text { feedback }\end{array}$ & $\begin{array}{l}\text { postdiction of } \\
\text { action effect error }\end{array}$ & fERN & FRN \\
\hline & & $\begin{array}{l}\text { movement } \\
\text { error }\end{array}$ & $\begin{array}{l}\text { external with } \\
\text { respect to } \\
\text { movement } \\
\text { (correctable } \\
\text { with respect } \\
\text { to action } \\
\text { effect) }\end{array}$ & \multicolumn{2}{|c|}{$\begin{array}{l}\text { no significant negative fronto- } \\
\text { central ERP }\end{array}$} & - & - & - \\
\hline
\end{tabular}

Studies are categorized with respect to (1) task, (2) type of error (movement error, action effect error, or movement error that gave rise to an error regarding the action effect), (3) source of error information (internal or external), (4) polarity, location, and timing of correlated ERP signals, (5) time course of error valuation (predictive or postdictive), (6) terminology (Ne/ERN or FRN) used by the corresponding authors, and (7) terminology proposed by the current article. Please note that not all authors cited used the classical differentiation of Ne/ERN and FRN after internal and external errors sources (e.g., Vocat; Anguera; Maurer/Joch; Krigolson and Holroyd, 2006), but terminology relatively congruent with that proposed here). 


\section{A proposal of ERP terminology}

When considering these studies on error valuation in complex motor tasks, it becomes apparent that not all authors adopt the ERP terminology that differentiates between external and internal error information. Hence, we propose an alternative distinction in terminology. First, we suggest to conceptually discriminate between movement descriptions and descriptions of action effects. To keep these characteristics properly separated, we will use Greek letters when referring to movement parameters, and Latin letters when referring to parameters describing action effects. Both are coupled by a (potentially) non-trivial function, e.g. resulting in a denotation like: $E=$ $f\left(\alpha_{1}, \alpha_{2}, \ldots, \alpha_{n}\right)$, where $E$ represents the action effect, and $f$ is the model of the true physical laws that connect the movement parameters $\left(\alpha_{1}, \alpha_{2}, \ldots, \alpha_{n}\right)$ to the effect. As stated earlier, an error is typically conceptualized as difference between an intended state and an actual state. Accordingly, when looking at errors in the action effect, it has to be considered what was intended to happen (denoted by $E^{*}$ ), and what actually happened $(E)$, and, respectively, what is expected or predicted to happen $(\hat{E})$. Both, $E^{*}$ and $\hat{E}$ are projections into the future $(t+\Delta t)$ on the basis of information at an earlier point in time $(t)$. For the predicted effect, this can, for example, be denoted $\hat{E}(t+\Delta t)=\hat{f}\left(\alpha_{1}(t), \alpha_{2}(t), \ldots, \alpha_{n}(t)\right)$, where $\hat{f}$ is the estimated model of the true physical model (prediction function) that predicts $\hat{E}$.

After having presented these definitions, we are in a position to define what we think is being reflected in the electrophysiological potentials being measured. According to the theory of hierarchical error processing based on Krigolson and Holroyd, the Ne/ERN and the FRN both reflect processing of high-level errors, while the Ne/ERN is suggested to represent pre-dictive error processing, and the FRN is suggested to correlate with post-dictive error processing. Thus, the FRN should indicate the result of the processing of information about the action effect after it has occurred (note that the observed difference in negativity should not be interpreted as a correlate of the processing of error information per se. Error information is processed in any case. However, negativity solely differs dependent on the result of this processing, i.e. whether or not an error is detected). To be precise, this information should be called terminal action effect feedback (TAEF), so as to differentiate it from the action effect that does not indicate the actual action goal (e.g., ball flight towards the basket in a basketball shot; see Fig.2). The modality in which the information about TAE is transferred, which parameters are actually used to describe the effect, or the source [internal vs. external] is not at all relevant for the question of whether this information can be called TAEF (and the corresponding time locked potentials (TAE)FRN accordingly). Following this definition, the FRN, representing a high-level error $E^{*} \neq E$, can only be observed after the terminal action effect $E$ has occurred.

The Ne/ERN, instead, reflects a prediction of the terminal action effect. The characteristics of the underlying information for this prediction are again (as in the TAEF information) not relevant in our opinion, as long as the information is not a TAEF. This can be better explained when examining the possible information sources for the prediction. In cases where the movement is identically described as its effect (e.g., button presses, tracking), information about the movement is the same as information about the TAE. Hence, predictive error processing is based on internal information (efference copy of motor command) alone in these cases. In contrast, when movement and action effect are distinct (e.g., in throwing), the prediction can be based on efferent as well as on sensory movement-related information, as long as it is not based on direct information about the action outcome. Here, lowlevel errors become important. Low-level errors are defined as discrepancies between the intended and the actual movement parameters (Krigolson and Holroyd, 2007b). They can, hence, be denoted as

$$
\begin{gathered}
\left(\alpha^{*}{ }_{1}(t), \alpha^{*}{ }_{2}(t), \ldots, \alpha^{*}{ }_{n}(t)\right) \neq \\
\left(\alpha_{1}(t), \alpha_{2}(t), \ldots, \alpha_{n}(t)\right) .
\end{gathered}
$$

Low-level errors, those that can be corrected, and as a consequence, do not violate the action goal, have been associated with posteriorly distributed ERP components (N100 and P300; Krigolson and Holroyd, 2007a), but not with fronto-central activity. This is not surprising, since it can be derived from the above equation that low-level errors do not directly project onto the action effect $E$. To link movement-related information to high-level errors, the prediction function $\hat{f}$ is required, allowing a projection along 
two dimensions, i.e. from one level of description to another (from movement to effect), and from the moment $(t)$ in time the data is available to a moment in the future $(t+\Delta t)$ when the effect will actually occur in reality. Hence, a high-level error occurs when $f\left(\alpha_{1}(t), \alpha_{2}(t), \ldots, \alpha_{n}(t)\right)$ inevitably leads to an $E(t+\Delta t)$ that is different from $E^{*}(t+$ $\Delta t)$. However, since $E(t+\Delta t)$ is not known at time $t$, the only reasonable way to compare the actual with the intended effect is to replace $E(t+\Delta t)$ by an estimate, i.e. $\widehat{E}(t+\Delta t)$, which can be considered a prediction of the TAE. In cases where the predicted TAE is evaluated as an error (high-level error), fronto-central activity in form of an Ne/ERN should be observable. Thus, to clarify once more: The labelling of error-related brain activation is independent from the modality and the parameters used; the defining distinction is whether this activation is based on a predicted effect or not.

In summary, errors can occur at two different levels: the movement execution level and the action effect level. Depending on the task, these levels can coincide or be viewed separately. Figure 2 illustrates different variables of the error valuation process in two different tasks, basketball shooting and button pressing. The main difference between the tasks is the separation between action and movement. While movement and action are identical in button pressing, the shooting action is not terminated with the end of the shooting movement represented by ball release. The ball still needs some time (about 1 second) to travel towards the basket after it has been released from the shooter's hand. Hence, TAEF is delayed with respect to the end of the movement. Prediction of the TAE can take place at roughly three different time points or intervals. First, internal information from the efference copy of the motor command is available after termination of movement planning for a comparison of the intended effect $E^{*}(t+\Delta t)$ with the predicted effect $\hat{E}(t+\Delta t)$. Second, sensory information about the movement is collected during movement execution. The matching of intended $\left(\alpha^{*}{ }_{1}(t), \alpha^{*}{ }_{2}(t), \ldots, \alpha^{*}{ }_{n}(t)\right)$ with actual movement parameters $\left(\alpha_{1}(t), \alpha_{2}(t), \ldots, \alpha_{n}(t)\right)$ gives rise to an updated prediction of $\hat{E}(t+\Delta t)$ and, hence, an updated comparison with $E^{*}(t+\Delta t)$.

It is important to recall that a high-level error is only detected in the case that a movement error cannot be corrected anymore (which is the case after the moment of ball release in throwing). A third comparison of $E^{*}(t+\Delta t)$ with $\hat{E}(t+\Delta t)$ can occur during the ball flight towards the basketball rim. Although certainty of the prediction increases with movement termination and the closer the ball gets to the rim, error valuation will remain a prediction as long as TAEF has not yet started (i.e., the ball has not yet passed the rim level). In contrast, TAE in the button press task can only be predicted after movement planning has been terminated. Deviations from the desired movement parameters that occur during movement execution cannot be processed and used to derive a predictive valuation of the TAE before the action is actually terminated, due to the shortness of the movement. Since movement end and action end are identical, error valuation after having pressed the button falls into the postdiction interval.

Depending on which error level or type (action effect or movement execution) one is interested in, trials have to be categorized into error trials and successful trials on their respective levels. That is, when analyzing movement errors, their categorization must not be based on the outcome of the effect level, but rather according to the average deviation of the movement trajectory or a similar characteristic. Thus, when an ERP signal emerges during the prediction interval (i.e., before TAEF) and correlates with an error on the effect level, it predicts this TAE-error. In contrast, when an ERP signal emerges during the prediction interval and correlates with a movement error (e.g., a trajectory error), it does not necessarily have a predictive function, since movement errors do not have to end in TAE-errors. This is confirmed by the study by Krigolson and Holroyd (2007a), who found a Ne/ERN that correlated with effect errors in a manual aiming task when the aiming error could not be corrected. In contrast, when participants were able to correct their aiming movements, the Ne/ERN was absent, and ERP signals with more parietal distributions were observed (see also Krigolson and Holroyd, 2006). In this regard, we propose the use of the term errorrelated for neural correlates of error valuation processes predicting a TAE-error, independent of the input source, the exact timing in the interval, or the task. Conversely, neural correlates would be termed feedback-related if they emerge after the 
TAEF in the postdiction interval.

\section{Classification of studies after ERP terminology}

To apply our proposal, we classified the previously described studies in Table 1 with respect to (1) task, (2) type of error (movement error or action effect error), (3) source of error information (internal or external), (4) correlated ERP signals, (5) time course of error valuation (predictive or postdictive), and (6) terminology (Ne/ERN or FRN).

\section{Conclusion}

To conclude, the classical terminology that differentiates the Ne/ERN and the FRN with respect to internal and external error information is unambiguous in tasks where low-level movement errors and high-level action effect errors coincide. In cases where a movement error leads to an action effect error only after a delay (e.g., tracking, throwing, shooting), ERPs can indicate the movement error, the prediction of the action effect error, and/or the detection (postdiction) of the action effect error. Similarly, error information can vary between efferent (internal), efferent and afferent (external), as well as solely afferent sources. Thus, it is important that these characteristics of error production and valuation are precisely defined in empirical studies, and that terminology is consistently used. Our proposal to choose Ne/ERN for the prediction of an action effect error and FRN for the postdiction of an action effect error is an attempt to clarify ERP terminology, especially for tasks where the action effect is dependent on the movement execution. It has to be pointed out that it was not within the scope of this focused review to address movement errors that do not lead to action effect errors (as investigated in de Bruijn et al., 2003; Krigolson and Holroyd, 2006, 2007a, and only observed in Krigolson and Holroyd, 2007b).
An alternative use of terminology to that presented here is that the Ne/ERN reflects internal sensory-prediction errors (which are action/execution oriented; motor control models), when the FRN reflects reward prediction errors (which are output-oriented regarding reinforcement learning theory; decision making theories; Torrecillos, et al. 2014). Hence, if a detected movement error (on the basis of a sensory prediction error signal) predicts a failure to reach an action goal (negative reward prediction), all ERP signals representing predictions regarding action outcomes/rewards should be termed FRN. This, in turn, would limit the Ne/ERN to movement errors with no clear predictive function regarding outcomes. This would only be the case in the studies of de Bruijn and colleagues (2003), and Krigolson and Holroyd (2007b) who, however, did not find negative fronto-central ERP signals that correlated with movement errors. Krigolson and Holryod (2006) also reported movement errors that did not lead to action outcome errors, because they could be corrected. However, they did not find fronto-central signals either, but negative occipital-parietal ERPs. Thus, in line with a postulation by Cavanagh (Cavanagh et al., 2012) that the Ne/ERN, the FRN and also the N2 reflect a single frontal midline theta-rhythm sensitive to mismatch signal in the service of behavioral adaptation, one could argue to confine the terminology of the error-related ERP signals to either the Ne/ERN or the FRN. However, it is unquestionable that temporally variable errorrelated ERP signals exist (early after movement onset vs. following outcome feedback), which also differ with respect to expectancy/surprise and error size, as well as within the learning process. Taking these differences into account, it seems advisable to express them through distinct terminology.

\section{Acknowledgements}

This research was funded by the Deutsche Forschungsgemeinschaft (DFG, German Research Foundation) - project number 222641018 - SFB/TRR 135 TP B6. 


\section{References}

Anguera JA, Seidler RD, Gehring WJ. Changes in performance monitoring during sensorimotor adaptation. J Neurophysiol, 2009; 102(3): 1868-1879. doi:10.1152/jn.00063.2009.

Bediou B, Koban L, Rosset S, Pourtois G, Sander D. Delayed monitoring of accuracy errors compared to commission errors in ACC. NeuroImage, 2012; 60(4): 1925-1936. doi:10.1016/j.neuroimage.2012.02.010.

Cavanagh JF, Zambrano-Vazquez L, Allen JJB. Theta lingua franca: a common mid-frontal substrate for action monitoring processes. Psychophysiology, 2012; 49(2): 220-238. doi:10.1111/j.1469-8986.2011.01293.x.

de Bruijn, ERA, Hulstijn W, Meulenbroek RGJ, van Galen GP. Action monitoring in motor control: ERPs following selection and execution errors in a force production task. Psychophysiology, 2003; 40(5): 786-795.

Desmurget M, Epstein CM, Turner RS, Prablanc C, Alexander GE, Grafton ST. Role of the posterior parietal cortex in updating reaching movements to a visual target. Nat Neurosci, 1999; 2(6): 563-567. doi:10.1038/9219.

Desmurget M, Grafton S. Forward modeling allows feedback control for fast reaching movements. Trends Cogn Sci, 2000; 4(11): 423-431. doi:10.1016/S1364-6613(00)01537-0.

Falkenstein M, Hohnsbein J, Hoormann J, Blanke L. Effects of crossmodal divided attention on late ERP components. II. Error processing in choice reaction tasks. Electroen Clin Neuro, 1991; 78(6): 447-455.

Gehring WJ, Goss B, Coles MGH, Meyer DE, Donchin E. A Neural System for Error Detection and Compensation. Psychol Sci, 1993; 4(6): 385-390. http://www.jstor.org/stable/40062567.

Gentsch A, Ullsperger P, Ullsperger M. Dissociable medial frontal negativities from a common monitoring system for self- and externally caused failure of goal achievement. NeuroImage, 2009; 47(4): 2023-2030. doi:10.1016/j.neuroimage.2009.05.064.

Hoffmann S, Beste C. A perspective on neural and cognitive mechanisms of error commission. Front Behav Neurosci, 2015; 9: 50. doi:10.3389/fnbeh.2015.00050.

Holroyd CB, Coles MGH. The neural basis of human error processing: reinforcement learning, dopamine, and the error-related negativity. Psychol Rev, 2002; 109(4): 679-709. doi:10.1037/0033-295X.109.4.679.

Holroyd CB, Nieuwenhuis S, Yeung N, Nystrom L, Mars RB, Coles MGH, Cohen JD. Dorsal anterior cingulate cortex shows fMRI response to internal and external error signals. Nat Neurosci, 2004; 7(5): 497-498. doi:10.1038/nn1238.

Jeannerod M. The neural and behavioural organization of goal directed movements. Oxford: Clarendon Pr; 1988.

Joch M, Hegele M, Maurer H, Müller H, Maurer LK. Brain negativity as an indicator of predictive error processing: the contribution of visual action effect monitoring. J Neurophysiol, 2017; 118(1): 486-495. doi:10.1152/jn.00036.2017.

Joch M, Hegele M, Maurer H, Müller H, Maurer LK. Accuracy of Motor Error Predictions for Different Sensory Signals. Front Psychol, 2018; 9: 1376. doi:10.3389/fpsyg.2018.01376.

Jordan MI, Rumelhart DE. Forward models: Supervised learning with a distal teacher. Cogn Sci, 1992; 16: 307354.

Kieffaber PD, Hershaw J, Sredl J, West R. Electrophysiological correlates of error initiation and response correction. NeuroImage, 2016; 128: 158-166. doi:10.1016/j.neuroimage.2015.12.046.

Krigolson OE. Event-related brain potentials and the study of reward processing: Methodological considerations. Int J Psychophysiol, 2018; 132(Pt B): 175-183. doi:10.1016/j.ijpsycho.2017.11.007.

Krigolson OE, Holroyd CB. Evidence for hierarchical error processing in the human brain. Neuroscience, 2006; 137(1): 13-17. doi:10.1016/j.neuroscience.2005.10.064.

Krigolson OE, Holroyd CB. Hierarchical error processing: different errors, different systems. Brain Res, 2007a; 1155: 70-80. doi:10.1016/j.brainres.2007.04.024.

Krigolson OE, Holroyd CB. Predictive information and error processing: the role of medial-frontal cortex during motor control. Psychophysiology, 2007b; 44(4): 586-595. doi:10.1111/j.1469-8986.2007.00523.x. 
Krigolson OE, Holroyd CB, van Gyn G, Heath M. Electroencephalographic correlates of target and outcome errors. Exp Brain Res, 2008; 190(4): 401-411. doi:10.1007/s00221-008-1482-x.

Lutz K, Puorger R, Cheetham M, Jancke L. Development of ERN together with an internal model of audiomotor associations. Front Hum Neurosci, 2013; 7: 471. doi:10.3389/fnhum.2013.00471.

Maurer LK, Maurer H, Müller H. Neural correlates of error prediction in a complex motor task. Front Behav Neurosci, 2015; 9: 209. doi:10.3389/fnbeh.2015.00209.

Miltner WH, Braun $\mathrm{CH}$, Coles MG. Event-related brain potentials following incorrect feedback in a timeestimation task: evidence for a "generic" neural system for error detection. J Cogn Neurosci, 1997; 9(6): 788798. doi:10.1162/jocn.1997.9.6.788.

Ridderinkhof KR, Ullsperger M, Crone EA, Nieuwenhuis S. The role of the medial frontal cortex in cognitive control. Science, 2004; 306(5695): 443-447. doi:10.1126/science.1100301.

Torrecillos F, Albouy P, Brochier T, Malfait N. Does the processing of sensory and reward-prediction errors involve common neural resources? Evidence from a frontocentral negative potential modulated by movement execution errors. J Neurosci, 2014; 34(14): 4845-4856. doi:10.1523/JNEUROSCI.4390-13.2014.

Vocat R, Pourtois G, Vuilleumier P. Parametric modulation of error-related ERP components by the magnitude of visuo-motor mismatch. Neuropsychologia, 2011; 49(3): 360-367. doi:10.1016/j.neuropsychologia.2010.12.027.

Walsh MM, Anderson JR. Learning from experience: event-related potential correlates of reward processing, neural adaptation, and behavioral choice. Neurosci Biobehav Rev, 2012; 36(8): 1870-1884. doi:10.1016/j.neubiorev.2012.05.008.

\section{Corresponding author:}

\section{Lisa Katharina Maurer}

Department of Psychology and Sport Science

Justus Liebig University Giessen

Kugelberg 62, 35394 Giessen, GERMANY

Phone: $\quad+49(0) 6419925234$

Fax: $\quad+49(0) 6419925239$

E-mail: lisa.k.maurer@sport.uni-giessen.de 